\title{
Automatic Switching of Three Phase Induction Motor during Fault Condition
}

\author{
Aswin.S, Jagadesh.P, Keerthi Aravind.S.P, Kesava Suriyan.P, Baranilingesan.I
}

\begin{abstract}
This paper proposes the automatic switching of a three-phase induction motor to provide an uninterrupted motor operation in industrial applications. To accomplish this aim, two motors are employed one is a primary motor and another one is a back-up machine that is automatically made switched on in the case of primary motor fails to operate. All the process is controlled by the Arduino controller design. Moreover, the continuous running of motors causes the motor temperature to rise, which is effectively handled by the proposed controller design, which automatically switches the primary and backup motor for every 24 hours. The motor operating status is automatically updated by means of GSM strategy to the operator. Here arduino controller used to control the induction motor with the help of relay. In the case of unexpected fault conditions, to protect the system both the motors are automatically switched off and a message is passed to the operator about the fault condition. The proposed methodology is experimentally validated by a hardware model with better working performance.
\end{abstract}

Keywords: Arduino Controller, Automation, GSM, Three-phase Induction motor

\section{INTRODUCTION}

The transportation of water is usually made by means of induction motors for industry and agriculture purposes. The uninterrupted water supply is highly necessary for an effective and safe mode of industrial operations and control. The motors are operated by means of manual control or automated, and in any case of malfunction in the motor the entire system becomes messy and it affects the whole process of the consumer or industry. So, it is highly significant to present some innovative proposals to handle above-stated problem statements in a cost-effective manner. This paper is intended to propose a novel control algorithm for effective

Revised Manuscript Received on August 15, 2020.

* Correspondence Author

Aswin S, UG Scholar, Department of EEE, KPR Institute of Engineering and Technology. Coimbatore, India. E-mail: theaswin@gmail.com

Jagadesh P, UG Scholar, Department of EEE, KPR Institute of Engineering and Technology. Coimbatore, India. E-mail: jagadeshhatrick@gmail.com Engineering and Technology. Coimbatore, India. E-mail: kesavasuriya@gmail.com

Keerthi Aravind S.P, UG Scholar, Department of EEE, KPR Institute of Engineering and Technology. Coimbatore, India. E-mail: swift.9516@gmail.com

Baranilingesan I, Assistant Professor, Department of EEE, KPR Institute of Engineering and Technology. Coimbatore, India. E-mail: barani.ling@gmail.com

(C) The Authors. Published by Blue Eyes Intelligence Engineering and Sciences Publication (BEIESP). This is an open access article under the CC BY-NC-ND license (http://creativecommons.org/licenses/by-nc-nd/4.0/)
Kesava Suriyan S*, UG Scholar, Department of EEE, KPR Institute of

industrial operation provided with an uninterrupted motor operation during fault conditions. The control algorithm is further extended to protect the machine from rising temperatures due to the continuous running of motors.

The three-phase induction motor fault identification and control is the most essential problem of consideration in the recent period of research [1], the ARM-based processer is programmed with the utilization of LabVIEW software, the motor operating status is continuously logged as a record, in the case of fault and over-temperature conditions the processer is programmed to take effective mitigation methods but which is not economical for small scale industries are a concern. The motor current signature analysis is made in the study [2], where online monitoring of the system is provided. In the case of continuous online monitoring, the data storage system becomes another issue to be considered. The fault detection in induction motor drive is an inevitable process [3], in this study the authors made an analysis of motor current and vibration signals by employing FFT and DWT. An ANN model is employed in the study [4], and the image processing based induction motor failure analysis made in [5]. But it is analyzed from the literature survey made is that numerous research is carried out in the area of induction motor fault analysis and it is highly necessary to present a better model that will handle this problem of constrain in an effective manner. And also as the proposed model is aimed to focus on industrial applications and agriculture applications the economic feasibility is also a main factor of consideration. So, the study is extended to search for simple controller design and it was identified that Arduino controllers can bridge these criteria. The Arduino microcontroller-based induction motor fault detection and protection study are presented in the paper [6], this model also presented a speed control strategy. The industrial data acquisition monitoring is presented in [6], various data collection methodologies are made in this study. A highly economically feasible model for motor fault detection based on Arduino is presented in the literature [7]. A real-time detection fault identification based on Arduino UNO is presented in the study [8]. An over-voltage protection model for a three-phase induction motor based on the Arduino controller is presented in the study [9], and the bearing and armature faults are diagnosed by the Arduino controller [10]. The following inferences are made from the above survey made:

- The fault diagnosis of the induction motors is highly necessary.

- The temperature handling of motors is an important problem of statement for better operation of the machine.

- The continuous operation of the motor is highly essential in industrial operations, but in the case of fault conditions, the tripper circuits are employed to

Blue Eyes Intelligence Engineering and Sciences Publication 


\section{Automatic Switching of Three Phase Induction Motor during Fault Condition}

remove the healthy section from the fault section.

- During fault conditions an unexpected loss of operation occurs, if the fault is not treated then the loss of operation continues for a prolonged time that is highly not reliable for industrial applications.

So, it is necessary to present a novel methodology that will make sure the continuous operation of the system during fault conditions. To address this problem of statement a novel model is developed in this paper discussed as follows.

\section{PROPOSED METHODOLOGY}

The proposed model is presented in Fig.1, the proposed control strategy has an Arduino controller to coordinate the proposed control mechanism. The main components of the proposed modeling include the stat to delta starter, the sensors such as voltage, pressure and speed, water filter, AC to DC converter, and the GSM module.

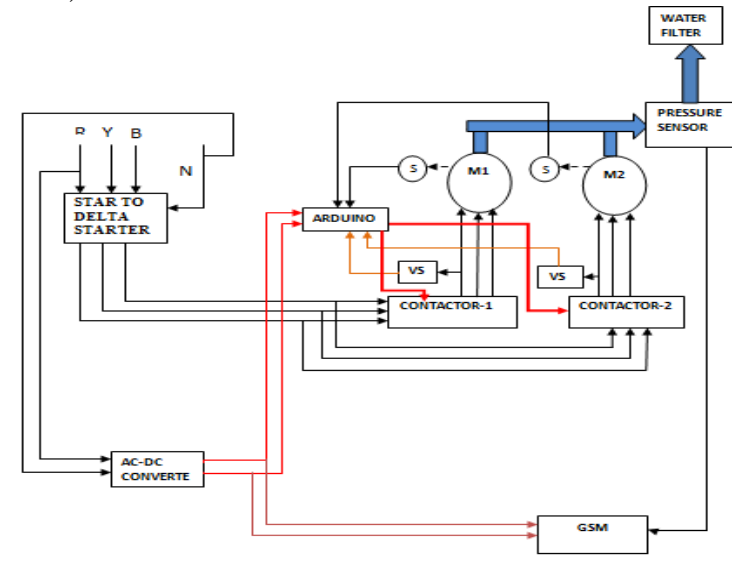

Fig. 1.Block diagram of the proposed model

\section{A. Three Phase Induction Motor}

Once the induction motor is energized by means of providing supply to stator windings, the flow of current in the coil induces a magnetic flux in the stator winding that will be linked with rotor winding by means of Faraday's law of electromagnetic induction.

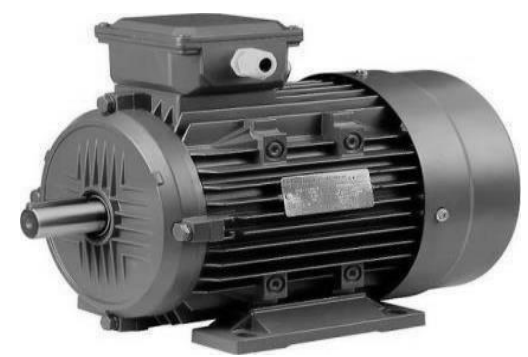

Fig.2. Induction Motor

The current starts flowing through the rotor windings such that rotor flux is generated along with stator flux. The stator flux will be in leading with respect to rotor flux that makes a rotating torque in the rotor. Now, the rotor starts to rotate in the direction of the rotating magnetic field. In the proposed study two motors are employed (M1 and M2), when M1 is employed as a primary motor then M2 is used as a back-up machine and vise versa. The typical motor employed in the proposed study as shown in Fig.2.

\section{B. Arduino Controller}

In the proposed study Arduino Uno is employed, it is a plug and play circuit with an onboard ATmega328P microcontroller as shown in Fig.3. It has 14 digital input/output pins (of which 6 can be used as PWM outputs), 6 analog inputs, a $16 \mathrm{MHz}$ quartz crystal, a USB connection, a power jack, an ICSP header, and a reset button. The pin configurations of the proposed model are depicted in Table-I.

Table- I: Pin Configuration

\begin{tabular}{|c|c|}
\hline Index & Specification \\
\hline Microcontroller & ESP8266 \\
\hline Operating Voltage & 3.3 \\
\hline Input Voltage & 3 \\
\hline Digital I/O pins & 16 \\
\hline PWM & $0-254$ \\
\hline Maximum current rating & $80 \mathrm{~mA}$ \\
\hline USB & Mini \\
\hline Analog pins & 1 \\
\hline Flash memory & 512 \\
\hline
\end{tabular}

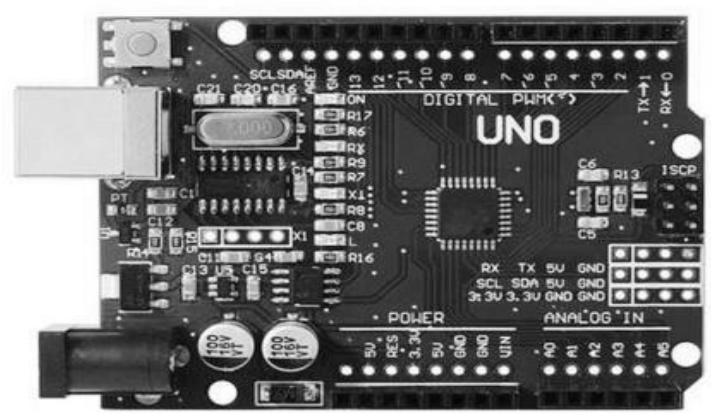

Fig.3. Arduino UNO board

The entire process is controlled by the proposed Arduino controller programming. The ATmega328P controller is programmed to coordinate the actions. The controller is interfaced with the motor system through $\mathrm{R}, \mathrm{B}, \mathrm{Y}$ lines through the bus bar connection.

\section{Contactor}

The contactors are employed for closing contacts for swing the operations, in the proposed modeling initially, two contactors are switched on by MCB, once the time of 24 hours is elapsed then another two contacts are employed for changing the primary motor to backup motor and vice versa. The typical contactors employed in the proposed system is presented in Fig.4.

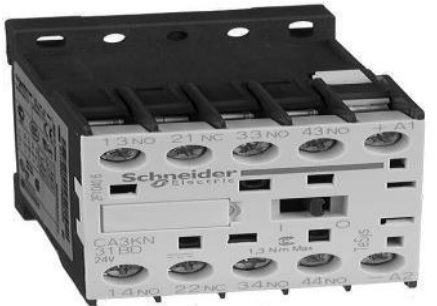

Fig.4. Contactor

\section{Rectifier Unit}

A rectifier circuit is designed to convert the AC to DC that is utilized for the powering of the controller circuit and sensor modules fixed in the system.

Published By:

Blue Eyes Intelligence Engineering and Sciences Publication

(C) Copyright: All rights reserved.

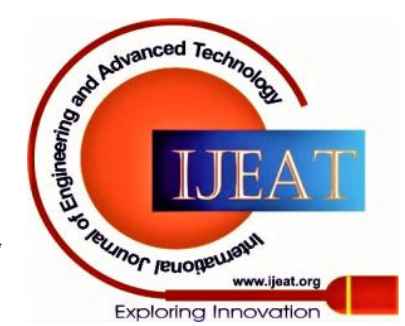


The rectifier unit designed in the proposed modeling is presented in Fig.5.

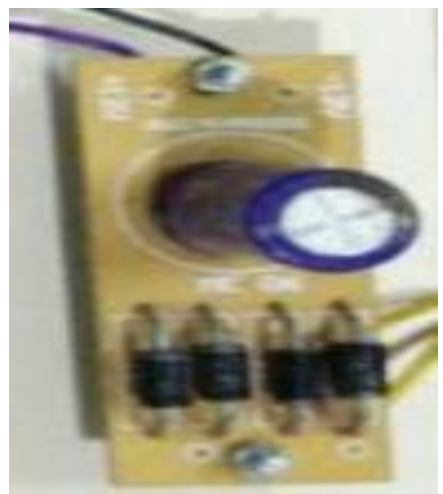

Fig.5. Rectifier Unit

\section{E. Timer Unit}

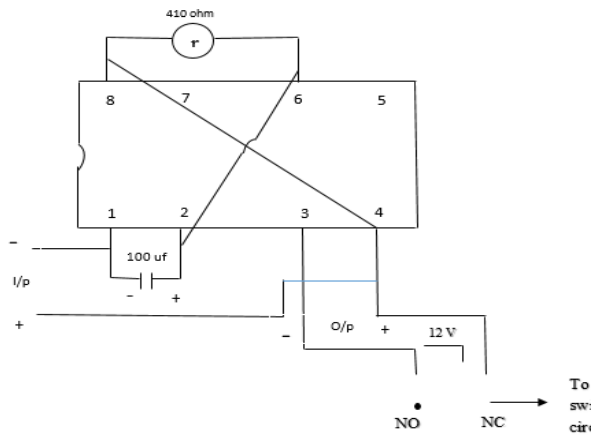

Fig.6. Timer Unit

The timer unit is made to ensure the working of motors by setting the contractor with a delay of 30-sec delay with both the motors. The timer unit is presented in Fig. 6

\section{F. IR Sensor}

The operating status of the motor is continuously monitored by the attached proximity sensor, in the case of any fault conditions the relay operates to isolate the healthy part of a circuit from the fault section. The proximity sensor is employed to identify the relay activity.

Once the relay operates to trip the primary motor then the controller makes contact with the backup motor to take the primary motor activity. The IR sensor employed in the proposed model is presented in Fig.7.

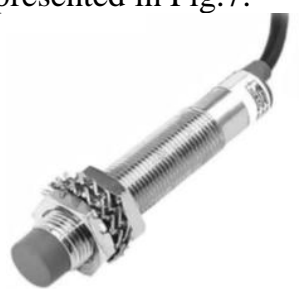

Fig.7. IR Sensor

\section{G. Communication Unit}

The final and most important unit is a communication module that is installed to provide the working status of the motors to the user. The Global System for Mobile communication module is programmed to send messages to the users such as based on the working status of the proposed model.

\section{RESULT AND DISCUSSION}

The proposed model is aimed to serve a two-fold purpose, to provide uninterrupted power supply a back-up motor is set to take the action under the scenario of primary motor fails to operate. And to control the heat generated in the motor, a switching algorithm is made between the motors such that for every 24 hours the primary and back-up motor is interchanged with their functions. The entire experimental setup is presented in Fig.8, the hardware specifications are reported in Table-II.

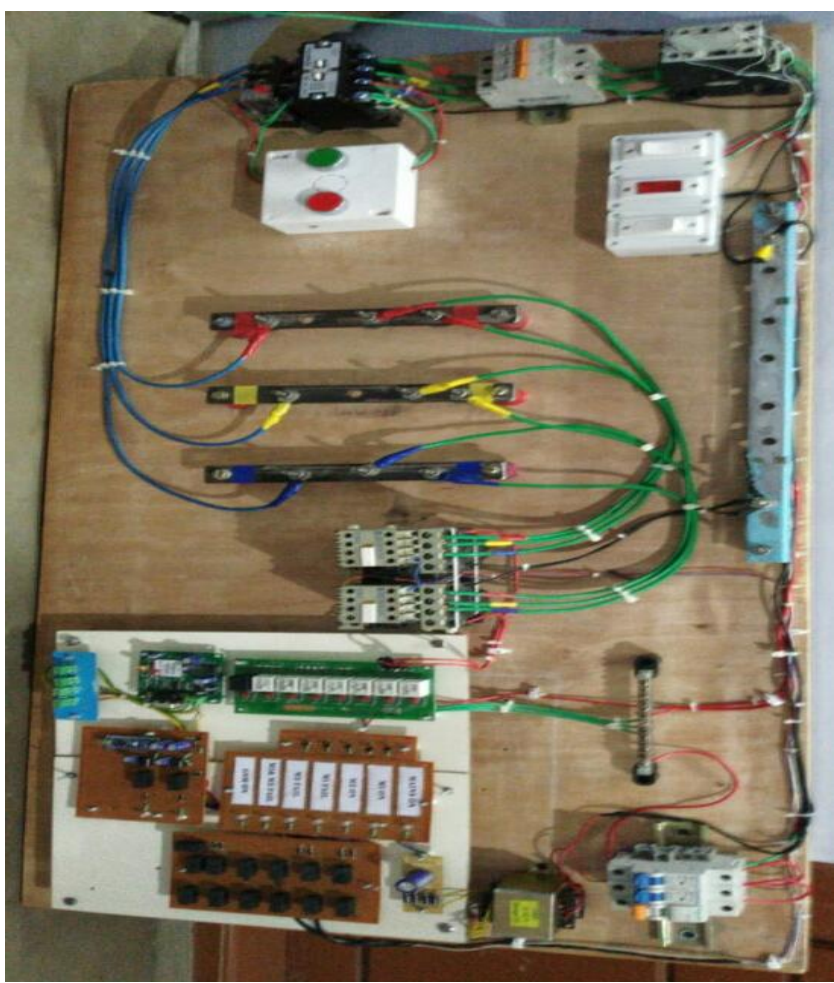

Fig.8. Experimental Setup of the proposed model

The Arduino controller is interfaced with the motor through the bus bars of $\mathrm{R}, \mathrm{Y}, \mathrm{B}$ Phase lines. Initially, the two contactors are switched by an MCB with the help of a pushbutton switch (green). The connections of bus bar wires initiate the motor to run. Another two contactors are used for the changeover of one motor to another motor. Relay is used to open the circuit when a fault occurs that is detected by the IR sensor. The entire controller circuit is powered by the designed rectifier circuit, the GSM module is programmed to send messages about the operating status of the motors such as ON, OFF, FAULT, and CHANGEOVER. Further, to make even the layman understand the operation LED indicators are fixed to indicate the working status of the motor such as MAIN ON, M1 ON, M2 ON, M1 FAIL, M2 FAIL as shown in Fig.9.

Table- II: Hardware Specifications

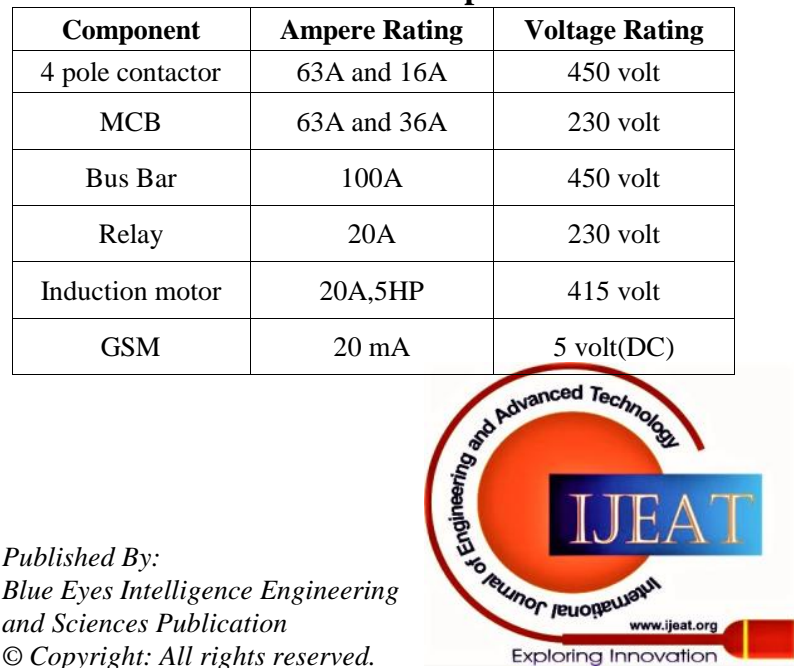


Automatic Switching of Three Phase Induction Motor during Fault Condition

\begin{tabular}{|c|c|c|}
\hline Component & Ampere Rating & Voltage Rating \\
\hline 4 pole contactor & 63A and 16A & 450 volt \\
\hline DC supply & 2A & 12 volt(DC) \\
\hline 4 pole contactor & 63A and 16A & 450 volt \\
\hline MCB & 63A and 36A & 230 volt \\
\hline
\end{tabular}

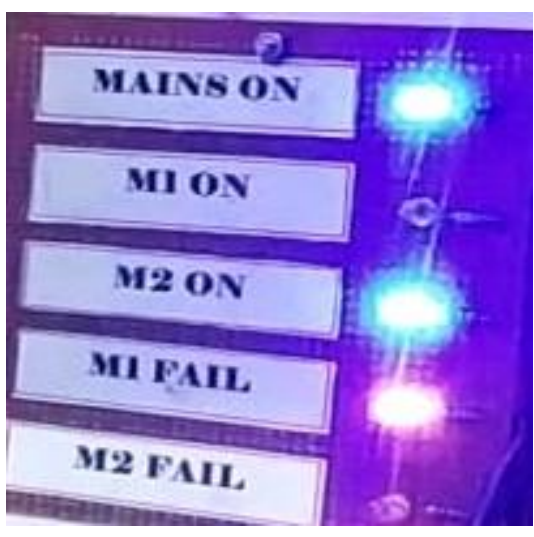

Fig.9. LED indicators representing the operation

Table-III Working Operation

\begin{tabular}{|c|c|c|}
\hline Sl. No & Working & Operation \\
\hline 1 & M1 OFF & M2 ON \\
\hline 2 & M1ON & M2 OFF \\
\hline 3 & M2 OFF & M1 ON \\
\hline 4 & M2 ON & M1 OFF \\
\hline
\end{tabular}

\section{CONCLUSION}

The continuous operation of motors is necessary for industrial applications, the sudden interruption of the operation during fault conditions result in a huge loss if the fault is not cleared for the prolonged time duration. On considering this requirement a novel methodology is presented in this paper based on cascading two motors, the primary and the back-up motor. The ESP8266 microcontroller is programmed to control the switching of motor operations during a fault condition and to reduce the temperature rise the motors are switched their operations every 24 hours. A GSM module is programmed to send a message to the user about the operating status of the system. The proposed model is designed with hardware circuits and validated experimentally to demonstrate the effectiveness of the developed strategy in this study.

\section{REFERENCES}

1. SandipJ. Murchite and Dr. S.A. Patil, 'ARM based Protection System for Induction Motor Against Faults', International Journal of Modern Trends in Engineering and Research, Vol. 01, No. 06, 2014.

2. NeelamMehala and RatnaDahiya, 'Motor Current Signature Analysis and its Applications in Induction Motor Fault Diagnostic', International Journal of Systems Applications Engineering \& Development, Vol. 02, No. 01, 2007

3. M. M. Rahman and M. N. Uddin, 'Online Unbalanced Rotor Fault Detection of an IM Drive Based on Both Time and Frequency Domain Analyses', IEEE Transactions on Industry Applications, Vol. 53, No. 4, 2017.

4. M. Kordestani, M. F. Samadi, M. Saif and K. Khorasani, 'A New Fault Diagnosis of Multifunctional Spoiler System using Integrated Artificial Neural Network and Discrete Wavelet Transform Methods', IEEE Sensors Journal, Vol. 18, No. 12, 2018
5. E. Resendiz-Ochoa, R. A. Osornio-Rios, J. P. Benitez-Rangel, R. De J. Romero-Troncoso and L. A. Morales-Hernandez, 'Induction Motor Failure Analysis: An Automatic Methodology Based on Infrared Imaging', IEEE Access, Vol. 6, No. 03, 2018.

6. R. Waswani, A. Pawar, M. Deore and R. Patel, "Induction motor fault detection, protection and speed control using arduino," 2017 International Conference on Innovations in Information, Embedded and Communication Systems (ICIIECS), Coimbatore, 2017, pp. 1-5, doi: 10.1109/ICIIECS.2017.8276071.

7. P. Sharma and S. R. Kapoor, "Evaluation of arduino based das for condition monitoring of induction motor," 2017 International Conference on Information, Communication, Instrumentation and Control (ICICIC), Indore, 2017, pp. 1-4, doi: 10.1109/ICOMICON.2017.8279084.

8. Dandale, Rahul and Chawan, Amol and Falke, Vaibhav and Patil, Dr. S .N., An Improved Method for Protection of Three Phase Induction Motor Using Arduino (May 18, 2019).

9. Article citation info: Boudiaf M, Cherroun L, Benbrika M. Real-time diagnosis of three-phase induction machine using Arduino-Uno card based on park's circle method. Diagnostyka. 2018;19(3):63-71.

10. Bhanvase, S.V., Damare, A.B., Mane, S.B. and Kumbhar, D.A., 2018. Protection of Three Phase Induction Motor from Over Voltage Review. International Research Journal of Engineering and Technology, 5(4), pp.2237-2239.

\section{AUTHORS PROFILE}

Aswin S., UG scholar, Department of EEE, KPR Institute of Engineering and Technology. Coimbatore. His area of intrest are Electrical machines and IoT.

Jagadesh P, UG Scholar, Department of EEE, KPR Institute of Engineering and Technology. Coimbatore. His area of intrest are Electrical machines and Power Electronics.

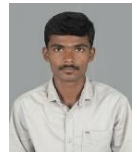

Kesava Suriyan S, UG Scholar, Department of EEE, KPR Institute of Engineering and Technology. Coimbatore. His area of intrest are Electrical machines, Digital circuits, app development and Python codings.

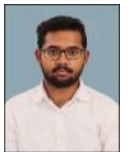

Keerthi Aravind S.P, UG Scholar, Department of EEE, KPR Institute of Engineering and Technology, Coimbatore.His area of intrest are Electrical machines and IoT.

Baranilingesan I, Assistant Professor, Department of EEE, KPR Institute of Engineering and Technology. Coimbatore. He has published articles in both national and international journals. His research interests are process control, instrumentation and sensors.
Blue Eyes Intelligence Engineering and Sciences Publication 